\title{
Çocuklarda Fleksibl Üreteroskopi Hangi Taşlara Uygulanır?
}

\author{
Eyüp Burak Sancak ${ }^{1}$, Tezcan Sezgin ${ }^{2}$, Berkan Reşorlu ${ }^{1}$
}

${ }^{1}$ Çanakkale Onsekiz Mart Üniversitesi, Tıp Fakültesi, Üroloji Anabilim Dalı, Çanakkale

${ }^{2}$ Çanakkale Kamu Hastaneleri Birliği, Çanakkale

\section{Giriş}

$\ddot{U}$ riner sistem taş hastalığının yaşam boyu prevalansı çeşitli çalışmalarda \%1-15 arasında bildirilirken, çocukluk çağı taş hastalığ $1<18$ yaş) bunun küçük bir kısmını (\%1-2'si) oluşturmaktadır $(1,2)$. Ancak son 2 dekatı aşkın bir süredir, özellikle adolesan dönem çocukluk çağı taş hastal1ğının insidansında belirgin bir artış söz konusudur $(3,4)$. Bu artıştan ise beslenme alışkanlıklarında meydana gelen değişiklikler ile artan obezite insidansı ve sedanter yaşam tarzı suçlanmaktadır. Yine erişkinlerde olduğu gibi çocuklarda da; kız cinsiyette taş görülme insidansı daha fazla artmaktadır. $\mathrm{Bu}$ durum da obezitenin, östrojenin taş oluşumundan koruyucu etkisini inhibe etmesine bağlanmaktadır (5).

Çocukluk çağı taş hastalığı aynı zamanda büyük oranda metabolik veya anatomik bozukluklara ya da enfeksiyoz patolojilere bağlıdır ve bu durum cerrahi sonrası $\% 55$ 'lere varan nüks oranınından sorumlu tutulmaktadır $(6,7)$. Önünde uzun bir yaşam beklentisi olan çocuklarda, nüks ihtimalinin yüksek olması ve tekrarlayan girişim gereksinimi minimal invaziv tedavi seçeneklerinin önemini daha da artırmaktadır. Son yıllarda gelişen teknoloji ile birlikte endoskopik cihazların minyatürizasyonunun sağlanması, lazer teknolojisinin gelişmesi, nitinol yapıda yardımcı enstrümanların kullanıma girmesi, endoürolojik girişimlerin daha yaygın kullanılır hale gelmesine ve artan deneyim ile birlikte çocuk hasta grubunda da uygulanır olmasını sağlamıştır $(8,9)$.

Aktif taş çıkarılması kararı verilen çocuk hastalarda tedavi seçiminde kullanılan endikasyonlar genel olarak erişkinler ile aynı kabul edilse de; çocuk hastalar özellikle şok dalga litotripsi (SWL) yöntemine oldukça iyi yanıt vermektedir $(1,10)$. Gelişmekte olan böbrek dokusunun şok dalgalarını daha iyi iletmesi, çocuklarda spontan pasajın erişkinlere oranla daha fazla olması, taş empadansının düşük olması, daha kısa ve elastik üreter mevcudiyeti bu hızlı yanıtta rol oynamaktadır. Bu nedenle çocuklarda, 20 mm'ye $\left(\sim 300 \mathrm{~mm}^{2}\right)$ kadar olan taşlarda SWL ilk tedavi seçeneği olarak önerilmektedir (1).

Çocuklarda $2 \mathrm{~cm}$ 'den küçük böbrek taşlarının tedavisi konusunda yapılmış çalışmalarda tek seans SWL tedavisi sonrası \%36 ile \%68 oranında taşsızlık sağlandığı bildirilmiştir (11). Tekrarlayan SWL seansları ile birlikte \%75 ile \%95 arasında taşsızlık oranları sağlanmıştır $(11,12)$. SWL başarısını azaltan faktörler arasında büyük taş boyutu, alt pol yerleşimi, taşın metabolik yapısı (sistin), kaliks boynu uzunluğu, infudibulopelvik açının 45 dereceden büyük olması ifade edilmektedir (13). Yine yapılan başka bir çalışmada taşın sertliğinin $\leq 600$ Hounsfield Unit olması ve taş boyutunun $\leq 12 \mathrm{~mm}$ olması başarıyı artıran faktörler olarak sıralanmıştır (14). İşlemin çocuklarda çoğunlukla genel anestezi gerektirmesi ve tekrarlayan her seansta anestezi gereksinimi oluşturması, radyasyona maruziyet, uzun dönemde renal skar, hiperoksalüri, hipertansiyon, diyabet veya kronik böbrek yetmezliğine neden olabileceği endişesi ve sistin gibi sert taşların (taş hastalarının \%8.5'u) bu tedavi yöntemine cevap vermemesi, bu yöntemin çocuklarda kullanımı konusunda çekinceler oluşturmaktadır $(2,8)$.

Çocuklarda 1985 'te Woodside ve ark.'larının ilk serilerini yayınlamalarından itibaren özellikle $2 \mathrm{~cm}$ 'den büyük böbrek taşlarının tedavisinde perkütan nefrolitotomi (PNL) sık tercih edilen tedavi yöntemlerinden birisi olmuştur (15). Başlangıçta, çocukların küçük boyutlu böbreklerine büyük enstrümanların kullanılmasının parankimal hasara neden olarak renal fonksiyon kaybına yol açabileceği, radyasyon maruziyeti, kanama ve sepsis gibi ciddi komplikasyon riskleri nedenleriyle pediatrik yaş grubunda PNL tedavisine ürologlar isteksiz yaklaşmışlardır. Ancak Jackman ve ark.'ları daha küçük trakt oluşturmanın daha az doku ve nefron yaralanmasına neden olacağını, özellikle küçük boyutta ve frajil yapıda böbreğe sahip çocuk hastalarda bu durumun daha da önemli olduğunu vurgulamışlar ve mini-perc tekniğini tarif etmişlerdir (16). Daha sonra yapılan pediatrik PNL serilerinin bir çoğunda, küçük boyutta enstrümanların kullanımı ile intraoperatif komplikasyon riskinin azaldığı gösterilmiştir, hatta komplikasyon oranlarını daha da azaltmaya yönelik tüpsüz PNL, mikro-perk gibi yeni modifikasyonlar tanımlanmiştır (17-19). Günümüzde PNL tekniği, büyük taş yükü olan çocuklarda, tüm yaş grupları için açık tedavinin yerini almış durumdadır. Ancak tüm bu modifikasyonlara ve yüksek başarıya rağmen, PNL sırasında komşu organ yaralanması, ciddi kanama, ürosepsis gibi major komplikasyonlar \%10'a varan oranlarda bildirilmekte ve bu işlemin gerçekten minimal invaziv bir girişim olup olmadığı tartışmaları sürmekte$\operatorname{dir}(20)$.

Retrograd intrarenal cerrahi (RIRS) yöntemi ile böbrek taşlarının tedavisi ilk defa 1983 yılında Huffman ve ark.'ları tarafından, renal pelvis yerleşimli büyük bir taşın rijid rodlens yapısına sahip bir üreteroskop ve ultrasonik litotriptör yardımıyla kırılması ile tanımlanmıştır (21). Ancak retrograd yoldan böbrek taşı tedavisinin yaygın kullanıma girmesi yıllar sonra fiberoptik teknolojiye sahip fleksibl üreteroskoplar (f-URS) ile nitinol yapıda yakalama aletlerinin geliştirilmesi ve eş zamanlı olarak Ho:YAG lazerin intrakorporeal litot- 
ripside kullanıma girmesi ile mümkün olmuştur. Pediatrik RIRS konusunda ilk geniş sayılabilecek seri ise 2007 yılında, Cannon ve ark.'ları tarafından yayınlanmıştır (22). Alt pol böbrek taşı nedeniyle RIRS uygulanan ve ortalama taş boyutu $12 \mathrm{~mm}$ olan 21 çocuk hasta ( $13 \mathrm{kız}, 8$ erkek) bu çalışmaya dahil edilmiş, ortalama 11 aylık takip sonunda $\% 76$ oranında taşsızlık sağlandığı ve hiçbir hastada intraoperatif ya da postoperatif komplikasyon gelişmediği bildirilmiştir. Ancak pediatrik seri olarak bildirilen bu yayında üst yaş limiti olarak 20 yaş (ortalama yaş 15.1 yıl) alınmıştır ve olguların büyük kısmı postpubertal (\%67) hastalardan oluşmuştur. Bu çalışmada başarı yüzdesi <15 mm olan taşlar için \%93, >15 mm taşlar içinse \%33 olarak bildirilmiştir. Yazarlar fleksibl URS'nin alt poldeki $<15 \mathrm{~mm}$ taşlar için iyi bir seçenek olacağını belirtmişlerdir.

Yine 2007 yılında Smaldone ve ark.'ları tarafından ortalama taş çapı $8.3 \mathrm{~mm}$ olan ve \%52'sinde taşın böbrek yerleşimli olduğu 100 pediatrik hastadan oluşan bir seride $\% 91$ oranında taşsızlık rapor edilmiştir (23). Bu çocukların $\% 9$ 'unda birden fazla işlem uygulanmıştır. Komplikasyon olarak \% 4.2 oranında perforasyon gerçekleşmiş ve bunlardan birisinde açık neosistostomi gerektiren striktür gelişmiştir. Philadelphia Çocuk Hastanesi' nin fleksibl URS deneyimlerini aktaran Kim ve ark.'ları ise, ortalama yaşı 62.4 ay (3 - 218 arası) olan, 167 çocuk hastada uyguladıkları 170 prosedürün sonuçlarını 2008 yılında rapor etmişleridir (24). Ortalama taş boyutu $6.1 \mathrm{~mm}$ (3-24 arası) olup, vakaların \%60'ında taşlar böbrek içi yerleşimlidir (\%28 üst üreter taşı, \%12 alt üreter taşı). Hastaların \%57'sinde üretere erişim sağlanamamış, bu nedenle stent yerleştirilerek pasif dilatasyona bırakılmıştır. Üreteral akses kılıf ise sadece taş yükü fazla olan ve pasif dilatasyon uygulanmış vakalarda kullanılmış; ancak ne oranda kullanıldığı çalışmada belirtilmemiştir. Ortalama 107 dakikalık (72-196 arası) ameliyat süresi sonunda, $10 \mathrm{~mm}$ 'den küçük taşlar için \%100, daha büyük taşlar için ise \%97 oranında taşsızlık elde edilmiştir. Bu seride aynı zamanda intraoperatif veya postoperatif (ortalama 19 ay takip süresi) hiçbir komplikasyon izlenmediği bildirilmiştir.

Yüksek başarı oranı bildiren bu çalışmaların aksi yönünde Tanaka ve ark.'ları 2008 yılında yapmış oldukları çalışmalarında ilk seans sonrası \%58, ikinci seans sonrası \%78 taşsızlık oranı bildirmiş; ayrıca ilk seferdeki taşsızlık oranının taş boyutu ve hasta yaşı ile ilişkili olup, taş yeri ile ilişkili olmadığını belirtmişlerdir. Okul öncesi çocuklarda bu işlemin başarısını araştıran Ünsal ve ark.'larının yapmış olduğu çalışmada, ortalama yaşı 4.2 yıl (10 ay-7 yaş) olan 16 çocuk hasta değerlendirilmiştir (8). Ortalama taş boyutu $11.5 \mathrm{~mm}$ (8-17 arası) olup, hastaların \% 37.5' i double-j stent ile başvurmuş (pasif dilatasyon), \%29.4'üne aktif dilatasyon yapılmış, \%17.6'sında ise üreteral akses kılıf kullanılmıştır. Taşı 10 mm'den küçük hastalarda \%100, daha büyük taşı olan hastalarda \%81 oranında bildirilmiştir. Bir vakada ise üreteral dilatasyon sırasında üreteral perforasyon oluşmuştur.

Yine puberte öncesi çocuklarda RIRS'ın etkinliğini değerlendiren Ghazaleh ve ark.'larının çalışmasında ise; 15 mm'den küçük taşı olan (ort. $12 \mathrm{~mm}$ ) 56 çocuk hastanın (6-14 yaş arası) sonuçları bildirilmiştir (25). Tüm hastalara prosedür öncesi pasif dilatasyon uygulanmış, taş kırma yöntemi olarak da elektrohidrolik litotripsi kullanılmıştır. Otuz dört aylık takip sonunda \%100 oranında taşsızlık elde edildiği, intraoperatif hiçbir komplikasyon gelişmediği, ancak postoperatif dönemde 3 hastada üriner enfeksiyon, 1 hastada ise makroskopik hematüri oluştuğu bildirilmiştir. Bu kadar yüksek başarı oranlarına rağmen, şu an yüksek komplikasyon oranları nedeniyle terkedilmiş bir litotripsi tekniğinin kullanılmasi, her hastaya pasif dilatasyon uygulanarak iki kez anesteziye maruz bırakılması ve renal pelvis içindeki taşların rijid URS ile kırılması bu çalışmadaki soru işaretlerini oluşturmaktadır.

Resorlu ve ark.'larının yapmış olduğu çok merkezli karşılaştırmalı analizde ise; 10-30 mm arası böbrek taşı nedeniyle mini-perk $(n=106)$ veya RIRS $(n=95)$ yapılan hastaların sonuçları karşılaştırılmıştır (26). Taşsızlık oranları RIRS için \%84, mini-perk için \%86; komplikasyon oranları ise RIRS için \%8.4, mini-perk için \%17 olarak bildirmişlerdir. Her iki grupta komplikasyonların tümü minör düzeyde olup, major komplikasyona rastlanmamıştır. Ancak mini-perk grubunda \%6 oranında transfüzyon gereksinimi olduğu bildirilmiştir. Bunun yanı sıra floroskopiye maruziyet, ameliyat süresi ve hastanede kalış zamanı RIRS grubunda daha kısa olarak bulunmuştur. Her ne kadar RIRS, mini-PNL'ye göre daha avantajlı görünse de; preoperatif faktörler değerlendirildiğinde iki grup arasında taş boyutu açısından anlamlı fark olduğu (23.7 mm vs $14.3 \mathrm{~mm}$ ) görülmektedir ve bu durum çalışmanın önemli bir limitasyonu olarak yazıda belirtilmiştir. Taş boyutuna göre gruplar tekrar karşılaştırıldığında, 1-2 $\mathrm{cm}$ arası taşlarda RIRS grubunda \%87, mini-perk grubunda $\% 100$ başarı elde edilmiş; 2-3 cm arası taşlarda RIRS grubunda $\% 50$, mini-perk grubunda $\% 84$ oranında başarı sağlanmıştır. Görüldüğü üzere taş boyutu $2 \mathrm{~cm}$ 'nin üzerine çıktığında RIRS başarısı belirgin olarak düşmektedir.

Yapılan güncel bir çalı̧̧mada da; yukarıda bahsedilen çalışmaları destekler biçimde RIRS'ın etkinliğinin ve güvenilirliğinin hasta yaşından etkilenmediği tespit edilmiştir (28). Günümüzde yaştan bağımsız olarak taş hastalığının tedavi endikasyonlarına baktığımızda; alt kaliks dışındaki lokalizasyonlarda taş boyutu $>2 \mathrm{~cm}$ ise PNL ilk tercih olmakla birlikte, 2 cm'den küçük boyutlu taşlarda ise SWL ilk önerilen tedavi yöntemidir. RIRS ise bu lokalizasyonlarda $15 \mathrm{~mm}$ 'den küçük taş boyutlarında önerilmektedir. Aksi halde rezidü kalma riski ile birlikte tekrarlayan endoskopik prosedür uygulama gereksinimi artmaktadır (1). Ayrıca diğer endoskopik tedavilerin uygun olmadığ 1 hasta gruplarında ya da cerrah ve/veya hastanın tercihi doğrultusunda RIRS'ın, >2 $\mathrm{cm}$ boyutlu taşlarda birden fazla seansta PNL'ye alternatif olabileceği de bildirilmektedir (27). Alt pol taşlarında ise taş boyutu $>15 \mathrm{~mm}$ olan olgularda SWL, yüksek rezidü oranları nedeniyle yerini PNL ya da RIRS'a bırakmıştır (1).

RIRS sonrası taşsızlık oranlarını öngörmek için yakın zamanda oluşturulmuş bir sınıflama Resorlu-Unsal Taş Skorlaması'dır (29). Bu siniflama hazırlanırken toplam 207 hastanın verileri değerlendirilmiş ve öncelikle RIRS başarısına etki edebilecek faktörler ortaya konulmuştur. Taş boyutu, sayısı, kompozisyonu, atnalı böbrek ve pelvik ektopik böbrek gibi böbrek anomalilerinin varlığ 1 ile infundibulopelvik açıyı içeren 5 faktörün RIRS başarısında etkili oldukları görülürken; yaş, cinsiyet, vücut kitle indeksi ve iskelet anomalileri varlığ1 gibi parametrelerin ise etkisi saptanmamıştır. $\mathrm{Bu}$ skorlama sistemi (RUS) kullanımı ve uygulaması son derece kolay bir yöntemdir. Orijinal çalışmada belirtildiği üzere RUS skoru arttıkça taşsızlık oranları belirgin şekilde azalmaktadır. Özellikle RUS skoru $\geq 2$ olan hastalarda RIRS yerine SWL veya PNL gibi alternatif tedavi yöntemlerin de ilk planda göz önünde bulundurulması yazarlar tarafından önerilmektedir. 
Son yıllarda teknolojik gelişmelerle birlikte popülaritesi artan RIRS yöntemi çocuklarda da küçük böbrek taşlarında SWL'ye, büyük böbrek taşlarında ise PNL'ye alternatif, etkin ve güvenilir bir tedavi yöntemi olarak ürologların tercihinde giderek ön sıralara yerleşmektedir. Hangi tedavi yönteminin seçilmesine karar verilirken; taşın boyutu, kompozisyonu, lokalizasyonu, üriner sistem anatomisi gibi faktörlerin yanı sira hasta ve ebeveynlerinin tercihi, mevcut ekipmanlar ve cerrahın tecrübesi de mutlaka göz önünde bulundurulmalıdir.

\section{Kaynaklar}

1. Türk C, Knoll T, Petrik A, et al (2014). Guidelines on urolithiasis. Available at: http://www.uroweb.org/gls/ pdf/20_Urolithiasis.pdf.

2. Desai M. Endoscopic management of stones in children. Curr Opin Urol 2005;15:107-12.

3. Srivastava T, Alon US. Urolithiasis in adolescent children. Adolesc Med Clin 2005;16:87-109.

4. Ost MC, Schneck FX. Surgical management of pediatric stone disease. In: Wein AJ, Kavoussi LR, Novick AC, et al. Cambell's urology. 10th ed. Philadelphia: WB Saunders, 2012;3667-85.

5. Penido MG, Srivastava T, Alon US. Pediatric primary urolithiasis: 12-year experience at a Midwestern Children's Hospital. J Urol 2013;189:1493-7.

6. Long CJ, Srinivasan AK. Percutaneous nephrolithotomy and ureteroscopy in children: evolutions. Urol Clin North Am 2015;42:1-17.

7. Milliner DS, Murphy ME. Urolithiasis in pediatric patients. Mayo Clin Proc 1993;68:241-8.

8. Unsal A, Resorlu B. Retrograde intrarenal surgery in infants and preschool-age children. J Pediatr Surg 2011;46:2195-9.

9. Unsal A, Resorlu B, Kara C, Bozkurt OF, Ozyuvali E. Safety and efficacy of percutaneous nephrolithotomy in infants, preschool age, and older children with different sizes of instruments. Urology 2010;76:247-52.

10. Mandeville JA, Nelson CP. Pediatric urolithiasis. Curr Opin Urol 2009;19:419-23.

11. Azili MN, Ozcan F, Tiryaki T. Retrograde intrarenal surgery for the treatment of renal stones in children: factors influencing stone clearance and complications. J Ped Surg 2014;49:1161-5.

12. Gofrit ON, Pode D, Meretyk S, et al. Is the pediatric ureter as efficient as the adult ureter in transporting fragments following extracorporeal shock wave lithotripsy for renal calculi larger than $10 \mathrm{~mm}$ ? J Urol 2001;166:1862-4.

13. Ozgur Tan M, Karaoglan U, Sen I, Deniz N, Bozkirli I. The impact of radiological anatomy in clearance of lower calyceal stones after shock wave lithotripsy in paediatric patients. Eur Urol 2003;43:188-93.

14. El-Assmy A, El-Nahas AR, Abou-El-Ghar ME, Awad BA, Sheir KZ. Kidney stone size and hounsfield units predict successful shockwave lithotripsy in children. Urology 2013;81:880-4.
15. Woodside JR, Stevens GF, Stark GL, Borden TA, Ball WS. Percutaneous stone removal in children. J Urol 1985;134:1166-7.

16. Jackman SV, Docimo SG, Cadeddu JA, et al. The "miniperc" technique: a less invasive alternative to percutaneous nephrolithotomy. World J Urol 1998;16:371-4.

17. Desai MR, Kukreja RA, Patel SH, et al. Percutaneous nephrolithotomy for complex pediatric renal calculus disease. J Endourol 2004;18:24-7.

18. Zeren S, Satar N, Bayazit Y, et al. Percutaneous nephrolithotomy in the management of pediatric renal calculi. J Endourol 2002;16:75-8.

19. Desai MR, Sharma R, Mishra S, et al. Single-step percutaneous nephrolithotomy (microperc): the initial clinical report. J Urol 2011;186:140-5.

20. Michel MS, Trojan L, Rassweiler JJ. Complications in percutaneous nephrolithotomy. Eur Urol 2007;51:899-906.

21. Huffman JL, Bagley DH, Lyon ES. Extending cystoscopic techniques into the ureter and

22. Cannon GM, Smaldone MC, Wu HY, et al. Ureteroscopic management of lower-pole stones in a pediatric population. J Endourol 2007;10:1179-82.

23. Smaldone MC, Cannon GM Jr, Wu HY, et al. Is ureteroscopy first line treatment for pediatric stone disease? J Urol 2007;178:2128-31.

24. Kim SS, Kolon TF, Canter D, et al. Pediatric flexible ureteroscopic lithotripsy: the children's hospital of philadelphia experience. J Urol 2008;180:2616-9.

25. Abu Ghazaleh LA, Shunaigat AN, Budair Z. Retrograde intrarenal lithotripsy for small renal stones in prepubertal children. Saudi J Kidney Dis Transpl 2011;22:492-6.

26. Resorlu B, Unsal A, Tepeler A, et al. Comparison of retrograde intrarenal surgery and mini-percutaneous nephrolithotomy in children with moderate-size kidney stone: results of multi-institutional analysis. Urology 2012;80;519-23.

27. Akman T, Binbay M, Ozgor F, Ugurlu M, Tekinarslan E, Kezer C, et al. Comparison of percutaneous nephrolithotomy and retrogradeflexiblenephrolithotripsy for the management of 2-4 cm stones: a matched-pair analysis. BJU Int 202;109:1384-9.

28. Gulpinar MT, Resorlu B, Atis G, Tepeler A, Ozyuvali E, Oztuna D, et al. Safety and efficacy of retrograde intrarenal surgery in patients of different age groups. Actas Urol Esp. 2015 Feb 6. pii: S0210-4806(14)00394-5. doi: 10.1016/j.acuro.2014.06.006. [Epub ahead of print].

29. Resorlu B, Unsal A, Gulec H, Oztuna D. A new scoring system for predicting stone-free rate after retrograde intrarenal surgery: the "resorlu-unsal stone score". Urology 2012;80:512-8.

Yazışma Adresi:

Berkan Reşorlu

Çanakkale Onsekiz Mart Universitesi, Tıp Fakültesi Hastanesi, Cumhuriyet Mah., Sahil Yolu, No: 5, Kepez, Çanakkale

Tel: +90 5336897268

Faks:+90 2862180393

e-mail:drberkan79@gmail.com 